\title{
The Transformation of Journalism: From Changing Newsroom Cultures to a New Communicative Orientation?
}

\author{
Leif Kramp and Wiebke Loosen
}

\subsection{INTRODUCTION}

Journalism is profoundly affected by a changing media environment that has contributed to an ever-increasing pace of innovation and a differentiation of media channels and platforms that simultaneously follows and fosters individualized media use. The digitalization of news media has enabled changes in news production as well as in news consumption, both on the level of individual practices and of organizational and social structures (cf. Klinenberg 2005; Paulussen 2012; Venkatesch and Dunkle 2013; Hermida 2014; Meijer and Kormelink 2015).

L. Kramp $(\square)$

ZeMKI, Centre for Media, Communication and Information

Research, University of Bremen, Bremen, Germany

e-mail: kramp@uni-bremen.de

W. Loosen

Hans Bredow Institute for Media Research, University of Hamburg, Rothenbaumchaussee 36, 20148 Hamburg, Germany

e-mail: w.loosen@hans-bredow-institut.de

(C) The Author(s) 2018

A. Hepp et al. (eds.), Communicative Figurations,

Transforming Communications - Studies in Cross-Media Research, https://doi.org/10.1007/978-3-319-65584-0_9 
In particular, social media have enlarged and multiplied the possibilities for public participation in journalism: Terms such as "participatory journalism" (Singer et al. 2011), “collaborative journalism” (Bruns 2005) or "network journalism" (Heinrich 2011) have been used to characterize how these trends affect the journalism-audience relationship and our understandings of and demands on journalism. Since the 1990s the major challenges confronting journalism - and research into it - has been seen in the developments around the internet and the new communicative conditions that came with it (for an overview see Mitchelstein and Boczkowski 2009). This illustrates that journalism as a genuine media phenomenon is intrinsically intertwined with the changing media environment which affects how journalism is produced, distributed and used by audiences (for a historical perspective see Birkner 2012).

Today, journalistic content is produced, used and distributed via multiple platforms, and social media increasingly complement traditional mass media while expanding the communicative options between journalists and their audiences. One consequence is an increased connectivity between journalists and audiences as well as an omnipresence of audience feedback: News organizations must now manage an increasing amount of audience-led comments, for example, in forums, comment sections and through user interaction on their social media channels which fundamentally changes how today's journalists and their audiences perceive, use and manage these kinds of interactions (Bergström and Wadbring 2015; Loosen and Schmidt 2016). The steady growth of user comments is probably one of the most notable examples in this context - and it illustrates that the idea of audience participation in journalism has changed relatively quickly over the past few years. What we are presently observing is a shift in the understanding of the comment section from being "a space for a new 'deliberative democratic potential' to emerge" (Collins and Nerlich 2015) to a necessary evil or even a threat to deliberation. ${ }^{1}$ As a consequence, and also owing to limited resources - and also because of a mixture of a certain professional distance towards their audiences, scepticism or even resistance against audience participation - there are already various examples of newsrooms that have completely shut down the comments sections of their websites. ${ }^{2}$

These developments should be seen in the context of a news industry struggling with disrupted business models and declining audiences (Phillips 2015), where one decisive challenge is to (re-)discover and 
(re-)engage audiences - also through new (social) media channels. Some of the newer journalistic media organizations in the field, for instance, start-ups such as the German Krautreporter or the Dutch De Correspondent, even explicitly build their foundations upon a new understanding of the journalism-audience relationship, for instance as a financer of crowdfunded projects (Carvajal et al. 2012), as collaborators in enterprises relying on crowdsourcing or as co-decision-makers.

Even if these developments neither follow a linear process nor take place simultaneously within all newsrooms or for all individual journalists, there is no doubt that "the audience" plays a much more central and explicit role in everyday newsroom routines than has been the case under the communicative conditions of mass media where journalism mainly observed its audiences via audience research and punctual feedback, for example, via letters to the editors. Generally speaking, this illustrates how the journalismaudience relationship is a mediated one and is subsequently changing with an expansion and differentiation of the media ensemble it is based on (for a historical perspective see Reader 2015). From the perspective of journalism (as a social field or system), media organizations (as enterprises), newsrooms (as journalistic organizations) and individual journalists (who may work in different contexts and under different conditions), these transformation processes inevitably lead to a tension between a (certain indispensable) professional distance towards their audiences and an increasing proximity that comes together with social media channels and their particular modes of communication. These spaces have become "meeting point[s]" (Bergström and Wadbring 2015: 140) for journalists and their audiences - meeting points where both groups meet on still 'uncommon ground'.

With this chapter, we want to discuss empirical evidence of this transformative stage for journalism in terms of its communicative orientation towards its audience(s). For this, we analyze empirical data from three of our recent surveys with the help of the approach of communicative figurations. It then becomes possible to identify patterns of a transforming communicative relationship between journalism and audiences.

\subsection{The Communicative Figuration of the Journalism-Audience Relationship}

One of the most often used notions to describe consequences of a changing media environment is "the notion of the blurring boundaries" (Loosen 2015) between communicator and recipient, the distinctions 
between whom are becoming increasingly porous. These fundamental changes in the media environment appear in journalism as if seen under a magnifying glass:

- Journalism's communication conditions are no longer solely characterized by mass media, but increasingly complemented by social media (e.g. Deuze et al. 2007; Singer et al. 2011).

- Consequently, journalism has become a form of "multichannel communication", that is, content is produced, distributed and used via various kinds of media and platforms; and these platforms are also used for various purposes: research, audience engagement, marketing, audience monitoring and so on (cf. Neuberger et al. 2014).

One main consequence of these developments is the expansion and the amplification of the communicative options between journalism and audiences, leading to a diversification and dynamization of roles and relations between them (Loosen and Schmidt 2012). There seems to be little doubt that the journalism-audience relationship is transforming in the context of continuous mediatization; that is, an interwoven change of media, culture and society. However, such a catch-all-diagnosis also conceals the fact that this transition follows neither a linear nor a simultaneous process for all segments of journalism, for all journalists or audience members. Thus, the vital question becomes how we can better assess and analyze this transformation theoretically and empirically.

Here, the concept of communicative figurations (Hepp and Hasebrink 2014) is helpful as it acknowledges three features of communicative interdependencies between individuals, collectivities and organizations that are of particular importance for the transformation of the journalism-audience relationship (cf. Hasebrink and Hepp 2016):

- A communicative figuration has a certain constellation of actors that makes up its structural basis.

- It has a dominating frame of relevance, a certain sense orientation that serves to guide its constitutive practices, and

- it is built upon specific communicative practices that draw upon and are entangled with a particular media ensemble.

We want to use this heuristic to describe the previously mentioned changes in the journalism-audience relationship systematically from a 
social constructivist perspective. Studying the transformation of the communicative figuration of the journalism-audience relationship requires a clear understanding of its social factors: the actors involved, their forms of communication (social interaction) and their shared frames of relevance which make up the basis upon which a communicative relationship is moulded and oriented (see Table 9.1).

Against the background of the above highlighted body of research and following Hasebrink and Hepp (2016: 4f.), we can identify five general trends in a changing media environment that are of particular relevance for journalism:

- The differentiation of media and communicative practices that also provides audiences with new chances to participate.

- Increasing connectivity between journalists and their audiences through these media and various technical intermediaries.

- The omnipresence of audience feedback and other contributions.

- An ever-increasing pace of innovation of media technologies and their use by journalists and audiences alike.

- The datafication and monitoring of audience behaviour based on increasingly diverse digital traces such as click rates and social media analytics that reveal information about news preferences, evaluation and engagement.

Obviously, these trends (can) have various consequences for journalism in general and for the journalism-audience relationship in particular (Loosen 2016). Here, the concept of communicative figurations helps us to reflect on how the journalism-audience relationship transforms with the changing conditions of media and communications - with respect to the communicative practices that are used by journalists and the audience, and the actor constellations in terms of who participates in the production and dissemination of news with respect to the dominating frames of relevance that characterize this relationship.

Therefore, if we very broadly define a point in time as the "pre-internet age" (tl) and compare that with "the internet and social media age" (t2), we can trace how the communicative figuration of the journalismaudience relationship has changed over time in terms of the dimensions described - and how it continues to change. With respect to the briefly outlined state of research, we come to the following orienting hypotheses: 


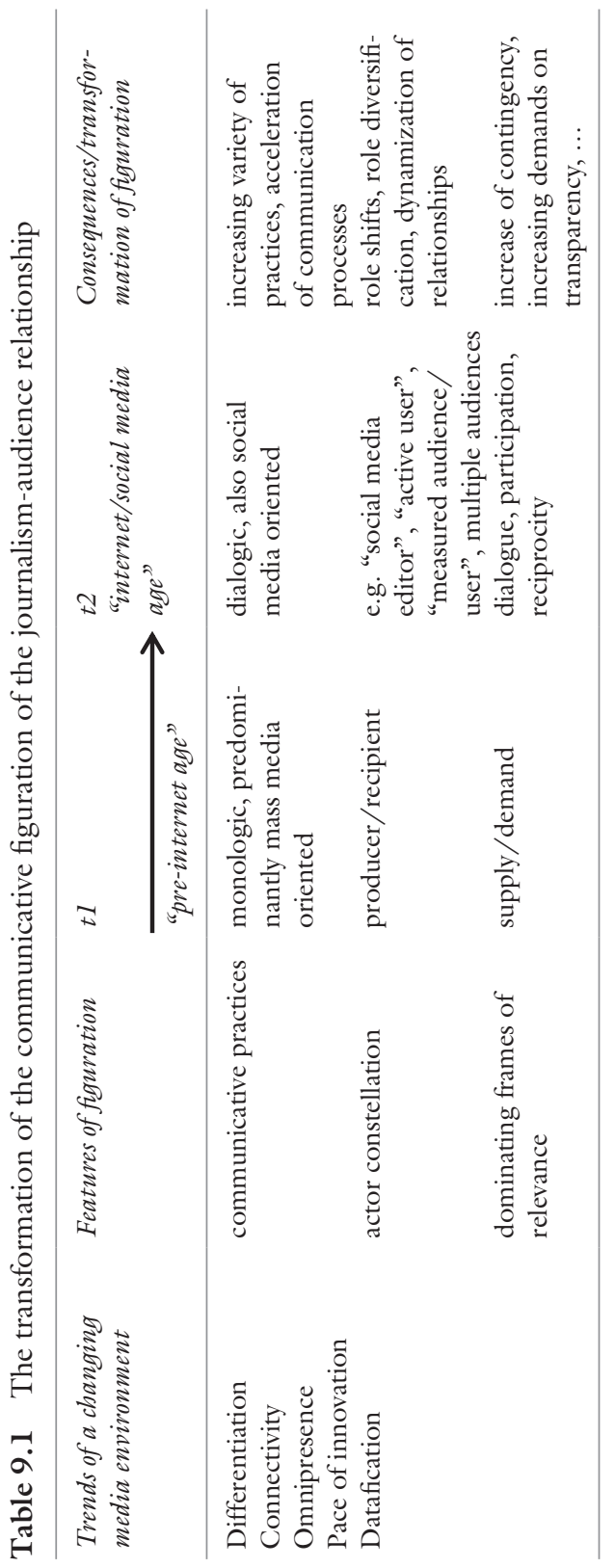


1. The communicative practices between journalism and (its) audiences are no longer only/predominantly mass media-oriented and monologic, but are increasingly social media-oriented and dialogic as well. Consequently, this transformation process leads to increasingly accelerated and varied communicative practices.

2. With respect to the actor constellation we can observe shifts and diversifications in the roles journalists and audiences play as well as the dynamization of their relationships: To differentiate between producer and recipient has become much too static. Instead we notice users operating at different degrees of participation, "measured audiences" coming together at different levels of aggregation and a multiplication of audiences media brands reach through a variety of platforms (e.g. via its printed edition or its Facebook page), which leads to a balancing act between "multiple audiences".

3. Overall, the defining characteristic of mass media - the asymmetry between journalism and audience in terms of supply and demand - is about to give way to a more reciprocal, participatory and dialogue-oriented framing. One effect of this is an increase of contingency because follow-up communication is, in a new quality and quantity, as visible as journalistic communication. Propositions are instantly discussed and criticized as well as stimulated by user contributions. Another consequence is an increasing demand for transparency - that is, for instance, that newsrooms and journalists increasingly discuss topic selections, ways of covering or not covering certain topics with their audiences.

Even if the three research projects we draw from in the following sections weren't already conceptualized and operationalized with respect to the concept of communicative figurations, it offers a fruitful framework to interconnect the different empirical evidence to trace and illustrate the changing nature of the communicative relationship between newsroom staff and audiences in a digital age. That is, we use communicative figurations as a theoretical lens through which we can reinterpret our empirical findings. Section 9.3 refers (1) to a survey among editors of German newspapers and (2) to in-depth-interviews with ten editors-in-chief of so-called "millennial news media" for young audiences in Germany (2.1). In Sect. 9.4 we switch and simultaneously widen the perspective by drawing on some empirical examples through a newsroom case-study 
that looks "at both sides of the story" (Schmidt and Loosen 2015) by looking at the (in-)congruence of mutual expectations between journalists and audience members.

\subsection{Tentative Openness and Structural Drawbacks in German Newspaper Newsrooms}

The following reflections on the communicative reorientation in German newspapers draw on two surveys that focus on the ongoing transformation of journalism practices in German newspaper newsrooms against the background of a changing (digital) media environment. The first study is a comprehensive survey of all newspapers in Germany with a complete editorial team ("publizistische Einheiten"). This survey was conducted in 2012 with a quantitative design and had a response rate of 56\% (cf. Kramp and Weichert 2015; Weichert et al. 2015). ${ }^{3}$ Its main question was: How and to what extent do newsrooms facilitate a reorganization of dominating frames of relevance in journalism with respect to its communicative orientation? The second survey was conducted in 2016 with a qualitative design, collecting the experiences and expectations of twelve editors-in-chiefs of millennial news media outlets in Germany, including Bento, BUNTEnow, BusinessInsider, Buzzfeed Germany, Brou, Headline24, HuffingtonPost Germany, jetzt, orange by Handelsblatt, Refinery29, Vice Germany and Ze.tt (cf. Kramp and Weichert 2016). ${ }^{4}$ In recent years, a considerable number of German publishing houses have launched specific news outlets that are geared towards attracting teenagers and young adults (summarized under the generational term "millennials"), encouraging them to engage with the news. They compete with other new market entries by international media corporations that have launched German subsidiaries and also canvas for a young target market that is characterized by an intensely digital lifestyle, but who are difficult to reach through the conventional news offerings of established newspaper websites (cf. Kramp 2016: 21f.).

Considering the two survey periods, the results of the studies can be understood as building upon each other in a transformative process in which publishers and newsrooms have tried to adapt to and even shape their changing (digital) media environment by changing their newsroom cultures and their communicative orientation towards audiences. In 2012, when the first survey was conducted, newspaper publishing in 
Germany had already been through a period of massive cutbacks and a continuous decline in circulation and advertizing revenue. By then, the industry had already been working on options to secure its core newspaper business and expand its digital outreach (cf. Esser and Brüggemann 2010; Kramp 2015). The subsequent development of alternative platforms, and new ways of attracting new (young) audiences by engaging them with interactive and participatory modes of mediating the news, not only corresponds with economical determinants but to journalists' professional perceptions of audiences' changing needs, demands and attitudes towards making news and its mediation as well. This combination of perceptions that change and the attitudes and demands that change with them constitute the wider transformation of the very communicative figuration that is the journalism-audience relationship.

\subsubsection{Changing Newsroom Cultures Through New Professional Roles}

Role conceptions in journalism are the result of a complex interdependence between self-perceptions and imposed expectations to fulfil normative and empirical functions (cf. Mellado et al. 2017). With the dawn of social media and its widespread dissemination, newsrooms became increasingly confronted with a continued differentiation, vast connectivity and the growing omnipresence of media affordances provided by digital information and communication technology (ICT). Journalistic roles were confronted with differentiated tasks and practices. Undertaking several efforts to adapt to this transforming media environment, the journalistic profession has experienced a rapid diversification with the implementation of various new professional roles that add to the existing range of tasks in integrated newsrooms (Bakker 2014): According to the 2012 survey, traditional roles still tend to dominate the self-perception of editorial staff in (German newspaper) newsrooms, and innovative job profiles seem to evolve in reaction to a communicatively interwoven public sphere encompassing new constellations of actors that include both journalists and audiences. These profiles can already be understood as the outcome of a professional reconsideration of journalism's efficiency in disseminating information and generating public interest for critical issues of broader societal relevance: An omnipresence of audience articulations (including feedback) and user-generated content has triggered an awareness that new tasks such as moderating the public discourse, editorial community management or curating social media content have 
emerged and that they should be taken seriously in the context of the newsroom. What these tasks have in common is that they are not so much focused on the production of original news content as they are on the mediation, classification and discussion of it by various (new) communicative practices through social media, with a strong emphasis on user dialogue.

The integration of additional professional fields with a variety of communicative requirements and orientations, which solidify into a range of job profiles and role perceptions, might not only change editorial procedures but also the social reality and self-perception of newsrooms. This is because it affects an adjustment of the dominating frames of relevance. This transformation process naturally depends on a variety of factors, including the particular nature and extent of the reorganization of professional roles. If a journalist's main task is to literally moderate a public discussion among members of the audience (and/or other journalists and public stakeholders), this means that a profound change in the communicative orientation of a newsroom that has previously been characterized by mass-media news production and distribution focus - or by a relevance frame of 'supply and demand' - occurs (see Table 9.1). If journalists act as managers of a community of users who share their opinions amongst themselves, who contribute their observations to their personal public spheres, who engage with the news dynamically, then we can see a significant change in newsroom culture: Against this background, the ability to master various emerging communicative practices in an everchanging (social) media environment becomes increasingly relevant for journalists. And, if a journalist lives up to a self-perception that places a special emphasis on the content of others circulating through social media by curating it for the sake of providing an overview of a complex discourse or issue, it also shifts editorial priorities.

Nearly half of the respondents $(48 \%, \mathrm{n}=127)$ in the 2012 newsroom survey identified the "community manager" as an increasingly relevant job profile in journalism. The approval rate was even higher for a prospectively increasing demand for journalists as "moderators" (66.1\%), "curators" (55.9\%) and "bloggers/commentators" (56.7\%). The formation of new role perceptions in the newsroom that place emphasis on follow-up communication with the audience and building and managing a community of users is a novelty in newspaper journalism, as reader service has formerly been a task undertaken exclusively by the marketing and public relations (PR) division of publishing houses (cf. Schoenbach 
et al. 1999). In 2016, editors-in-chiefs of millennial news media do not only confirm the high(er) relevance of journalistic roles that focus on audience engagement. Social media are at the centre of newsroom activities for both the subsidiaries of established newspaper companies and for newly established digital news organizations that exclusively address adolescents and/or young adults. Here, facing young, volatile, media users, the dominant frame of relevance has shifted towards a systematically dialogic communicative orientation towards audiences. Here, according to the surveyed editors, each and every journalist is expected to also act as a moderator, curator, community manager and blogger/commentator. In addition, the editorial staff of millennial news media are generally quite young, belonging almost exclusively to the very same generation that is targeted by the new editorial strategies (e.g. the age array at the newsroom of orange by Handelsblatt is 16-22 years, according to its editor Hans-Jürgen Jakobs). As stated by the surveyed editors of the millennial news media, the recruitment of young journalists is often focused on digital literacy in terms of an inherent understanding of and affinity towards emerging communicative forms in the digital ecosphere. Although classic journalistic competencies stay relevant, experiences in social media content production, networking expertise and the willingness to experiment with emerging media technologies are considered to be equally important.

\subsubsection{Differentiating the Media Ensemble}

Only $43 \%$ of the respondents in the newspaper newsroom survey stated that they would agree to focus on news that was interesting for a broad audience; one of the most supported role perceptions traditionally attributed to journalists (among themselves) related to the key idea of objective reporting (Weischenberg et al. 2012: 213-215). Here, it had by far the lowest approval rate for all surveyed items.

We consider this an indicator of the shifting priorities of communicative orientation for journalists: from a traditional mass media news dissemination perspective to a differentiated media ensemble with an audience that is fragmented and/or, indeed, "multiple audiences" (Hasebrink 2008, own translation) - it appears that journalists are increasingly acknowledging that they serve different audiences via different media channels and platforms during their daily work routines (Loosen and Schmidt 2016b). This is corroborated by the relevance 
that is ascribed to social networks in the newsroom compared to other internet services: More than $70 \%$ of the respondents deem social networks "very important" or "important" for their everyday work with an average approval rate of 2.2 ( $1=$ very important, $5=$ unimportant); all other surveyed items had lower approval rates (blogs 3.6, podcasts 3.9 , video 2.8, Twitter 3.0, data-driven journalism 2.6). A high level of importance placed on social networks is mentioned particularly by those respondents who think that community management will become more important for journalists in the future. This also points to the increased relevance of interactive and dialogic formats and practices in journalism. The results in detail:

- For younger journalists (39 and younger) social network services such as Facebook, Xing and Google+ are by far the most important online platforms for their editorial work. They also use short messaging services such as Twitter and appreciate video as a new form of mediation within integrated newspaper newsrooms as well as methods for data visualization.

- For middle-aged journalists (40-49) social web and data-driven journalism is the first choice when it comes to online activities. They also consider short messaging services and video important for their reporting. Blogs and podcasts, however, are deemed mostly unimportant.

- For older journalists (50 and over) Facebook and other social networks, data visualization and video are the most important online activities in the context of the newsroom, but Twitter is also considered relevant. Blogs and podcasts are regarded as rather conventional and less innovative forms of journalism practice compared with social networking and more challenging multimedia formats.

The relevance of online communicative interaction with the audience relates to both research tasks in everyday news production and content distribution. Journalists increasingly participate in the versatile distribution of (their) content by posting and sharing on social media.

This differentiation of media ensembles in the distribution of editorial content has been encouraged in a concerted effort to reach younger audiences with news content. Millennials are regarded as crucial for the future development of the news environment (cf. Poindexter 2012). Attracting young media users is in many respects challenging for 
traditional news organizations: With a declining readership for massdistributed news products, young consumers do not necessarily develop an affinity to legacy media as former generations have done in the past (cf. Duggan 2015a, b; Newman et al. 2016). Instead, they tend to turn towards digital media affordances that are not necessarily provided by established news organizations, but might lack a journalistic background (e.g. user-generated content by 'YouTube stars'; marketing, public relations or propaganda content disseminated virally through social networks; direct messaging/group communication). Furthermore, a considerably large body of research suggests that the respective millennial audience, born between the early 1980s and the late 1990s, is not at all a group of coherent interests and habits, but that its members are on the contrary as heterogeneous in their life plans as they are volatile in their preferences towards and motivations for using (mainly) digital media (cf. Albert et al. 2015; American Press Institute et al. 2015; Deloitte 2016).

This has stimulated editorial strategies that resulted in the emergence of millennial news media such as Ze.tt (an online venture of the German weekly Die Zeit), orange (the young subsidiary of the financial daily Handelsblatt) and Headline24 (a news portal for young audiences by the local media group Dr. Haas). As the 2016 survey shows, these media still operate a website as a steady destination for loyal users, but also as a hub that is connected to a multitude of social media platforms, channels and accounts operated by newsroom staff and actively engages with other users by distributing content in various ways and formats. According to all the editors of millennial news media that we surveyed, most users consume, share and comment on the news through Facebook, diverting it to a wide array of other communication services and social networks. For the responsible editors, this is a main driving force to not only adopt a "viral seeding" strategy (Sebastian Horn, Ze.tt) from marketing to expand their outreach to younger audiences, but even more so to develop distinctive news concepts for every single popular social media service, such as Facebook, Instagram, WhatsApp and Snapchat. This is pursued in the knowledge that this might lead to a procession of dependence on social media providers that are incrementally behaving like publishers themselves. However, assessing advantages and disadvantages, the surveyed millennial news media continue to walk a "thin line" (Juliane Leopold, Buzzfeed Germany) between not surrendering themselves to these uncontrollable social media partners and to gain as much valuable target group coverage as possible. 


\subsubsection{Adapting to the Communicative Habits of the Audience}

The ways millennial news media address adolescents and young adults are striking. Editorial strategies among the surveyed newsrooms mainly focus on two aims: first, to contribute to the conversations among users on social networks and messaging services such as WhatsApp, Facebook Messenger and Snapchat, and, second, to build an audience for their news brand. Therefore, the integration of social media concepts into newsroom practices does not necessarily have a supplementary character, but rather is more in line with the core of editorial self-perception. This communicative orientation is comparably radical: In order to attract young audiences with news, millennial news media strive to engage them with it. In doing so, they adopt various prevalent and emerging forms of communication that are used by adolescents and young adults and adapt their reporting to these communicative forms: from, for instance, interpersonal messaging to posting personal pictures and videos to circulating internet memes through peer networks.

Theoretically, against this background, users could also become a more active part of the news-making process - not only as a source, but also as a collaborator or as a corrective to false information mediated by journalists: This might be the case if a newsroom manages to successfully engage users to systematically contribute observations or even private research endeavours on public issues and versatile constructive feedback on editorial content. ${ }^{5}$ However, the communicative figuration between newsrooms and audiences is clearly more complicated than that. Even for millennial news media, the interviewed editors-in-chief note in surprising unity that user feedback would be an important factor in the editorial strategy. However, besides sharing feedback, the audience would not - yet - be as interested in contributing original content to news production as it could be, for example, on their personal living environment (in terms of hyperlocal citizen journalism). Therefore, a constructive inclusion of the audience into editorial processes of news-gathering remains a long-term perspective for some of the newsrooms.

With respect to the 2012 survey on transformations in newspaper newsrooms, a fundamental hesitation towards user participation in traditional areas of expertise in newsroom work prevails (Robinson 2010). According to the results of the survey, readers were hardly 
integrated into news production at all. To some extent, journalists welcomed the participation of readers while doing research (e.g. "crowdsourcing"): $11 \%$ of the journalists surveyed stated that reader participation is high when it comes to research; $33 \%$ said that it was at a normal level. Rather unpopular in news making contexts is user participation as a corrective: Only $22 \%$ of the respondents answered that users would participate like this in their editorial work. Other forms of participation such as contributing to the editing process or joining newsroom conferences (or the respective decision-making procedures) virtually or in person are widely ruled out, with $96 \%$ and $88 \%$ of respondents stating that this is not offered by their newsroom.

Participation in journalistic research can be understood in various ways and should be relativized. Journalists might not only think of it as helpful input for their research but also ascribe a certain relevance towards user-generated material such as photographs or notifications about opinions or complaints that are sent in. Therefore, we asked a further, more specific, question about whether the respondents would be willing to collaborate with readers if working on more complex and difficult issues. Here, the results demonstrate a hesitant reaction: $40 \%$ of the respondents had a neutral attitude towards the participation of users in this context. A third would let users participate, but more than a quarter were strictly against collaborations of this kind. We checked how strong the participation options correlate with other activities. The 2012 data show that there were significant correlations for all surveyed participation options. Therefore, if the reader is provided with an opportunity to participate in editorial research, it is also likely that he or she participates in other editorial contexts. However, in the case of sophisticated or sensitive stories that are deemed important by the journalist we found a negative correlation (Fig. 9.1).

Nonetheless, the surveyed journalists did not feel extraordinarily distant from their readers: more than half of the respondents were undecided. They stated that their readership was neither "far away" nor "very close" in terms of the assumed professional distance to the newsroom. Approximately one third of respondents attested to their newsroom as having a relatively close proximity to its readers. The overall professional distance between newsrooms and audiences was rated significantly lower ( 2.64 at $\mathrm{l}=$ very high, $5=$ very low) than the attitude towards user participation might suggest. An explanation for this difference might be the 


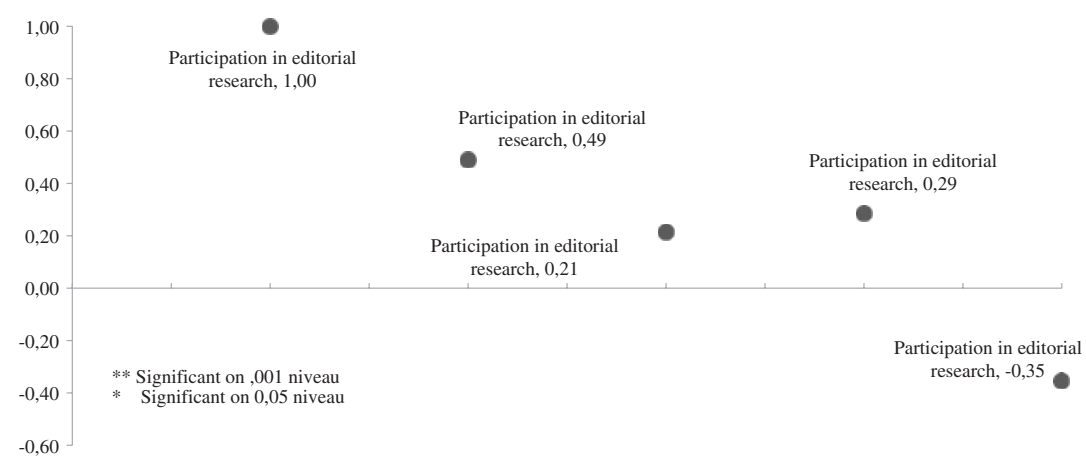

Fig. 9.1 2012 survey on transformation in newspaper newsrooms: willingness to let the reader participate in editorial research correlated with further options to participate. Pearson corr., sign. both sides; $\mathrm{N}=127$

multi-factorial nature of professional distance that does not only comprise readers' participation in editorial activities, but also the editorial performance in relation to the reader. It is therefore conceivable that the editors think they take up and reflect the needs and desires of their audience in their articles to the correct degree.

Furthermore, the perceived distance to the reader is significantly lower for respondents who have a higher approval rate for the increasing relevance of the "community manager" role. Journalists who see a demand for their profession to adopt a stronger moderation and dialogic job profile tend rather more to involve their readers in their research and publication of a story. However, the results suggest that newspaper newsrooms in Germany (still) do not show a systematic involvement of audiences in their editorial workflows. Instead, editorial cultures in newspaper companies are evidently still dominated by a decades-old mass media approach characterized by very few participation options for users. Strong inertial forces seem to be at play, at least in newsrooms that address a wider audience of all ages.

The results show a divergence between general news media and those that target younger audiences. As nearly all interviewed editors-in-chief of millennial news media emphasized that their editorial strategy explicitly excludes a regular editorial exchange of knowledge and developed formats between their respective venture and their parent company, this gap might grow even further. 


\subsection{Mutual Observation: Participatory Expectations and Attitudes of Journalists and Audience Members}

In this section, we switch the perspective by drawing on empirical examples of a newsroom case study while simultaneously widening it by "including the audience in journalism (research)" (Loosen and Schmidt 2016a). That is, we take both journalists and audiences into theoretical and methodological account by considering both groups in the actor constellation of the journalism-audience relationship. Since journalism research mainly focuses on the journalist as the central actor or role in the field, the journalist is considered the basic unit of empirical investigation and as such the primary social address or access point for data collection. However, if we deem the transformation of the journalism-audience relationship from a communicative orientation towards "supply and demand" to one of "dialog and participation" as a remarkable process (see Table 9.1), we consequently take a step further which means that we need to widen our focus by including not only journalists but audiences as an empirical subject into journalism research as well (Costera Meijer 2016).

To achieve this we will draw on a research project on audience participation that investigated how increasing opportunities for audience participation and expanding communicative options between journalists and their audiences, in light of a changing media environment, reshape the relationship between journalism and its audiences in four case studies of German journalistic outlets. ${ }^{6}$ The special character of this research lies in the fact that the theoretical frame and empirical design were chosen to assess and compare participatory practices and related expectations for journalists and audience members within one integrated framework. The project followed a multi-method design that combined in-depth interviews and online surveys with standardized content analyses (of journalistic output, user comments and participatory features on news sites) (Loosen and Schmidt 2016).

The data we present here were collected in July 2013 (a survey of journalists) and October 2013 (an audience survey), via online surveys among journalists and audiences. For this chapter, we focus on one of the four case studies, that of the German national newspaper Süddeutsche Zeitung and on two selected findings (Heise et al. 2014). These are related to a theoretical construct we term "inclusion distance" - understood as the extent of congruence and/or mismatch of inclusion 
expectations journalists and audience members hold (Loosen and Schmidt 2012; Schmidt and Loosen 2015). Among journalists, these inclusion expectations consist of journalistic role conceptions, images of the audience, its place and its function within journalistic practices and their assumed motivations for participation, as well as some general and strategic considerations of media organizations when it comes to audience participation. Among the audience, inclusion expectations consist of motivations for participation, the importance placed on participatory features and their general expectations of journalism and its functions.

We consider journalistic role conceptions and the (assumed) importance of participatory features the two richest aspects in the context of this chapter as they represent, in particular, "the tension between professional control and participatory openness" (Lewis 2012) - influencing a shift in, or at least an expansion of, the dominating frames of relevance in the journalism-audience relationship from "supply and demand" to "dialogue and participation" (see Table 9.1). Moreover, the concept of journalistic role conceptions is one of the classic tropes in journalism research (Weaver and Wilhoit 1986; Cassidy 2005; Mellado 2011; van Dalen et al. 2012; Mellado and van Dalen 2013) that helps us understand whether journalists consider themselves as mainly independent from audience influence (i.e. as a "gatekeeper" who provides a mass audience with objective information), as partners in a conversation with audiences, or if they aim to "stand up for the disadvantaged population" (Weischenberg et al. 2012: 214). For our purposes, we complemented the established scales to measure journalistic role conceptions with new participation- and dialogue-oriented tasks. ${ }^{7}$

To assess the mutual expectations of journalists and audience members the respective item batteries were worded in parallel in both the journalist and the audience surveys, and the same answer scales (fivepoint Likert scales, e.g. "agree completely" to "disagree completely" and "very important" to "very unimportant") were given, while the question text was directed to either one's own expectations or the assumed expectations of the other side.

In each case study, the differences between journalists' and users' mean item assessments are used to measure inclusion distance. Mathematically, we subtract for each item of the users' mean from the journalists' mean. Thus, the sign of the difference shows whether journalists rate the item higher (positive sign) or lower (negative sign) than their audience. The value of the differences in means conveys 
information about the extent of congruence. Table 9.2 shows that the difference in mean is already becoming highly significant with the absolute value of 0.36 ; below that, differences can be significant as well but need to interpreted with caution.

The mean scores and the differences in the assessments of journalists and audiences become clearer if we present the data not only in tables, but also in a particular visualization which enables the identification of patterns in the data (Schmidt and Loosen 2015): see Fig. 9.2. In this way, each item becomes a data point that is placed on a two-dimensional plane according to its mean value among journalists ( $x$-axis; scale from 1 to 5 ) and audience members ( $y$-axis; scale from 1 to 5 ). A diagonal line from bottom left to top right indicates those points where the mean values for journalists and audience members are identical. Thus, the closer an item is to the diagonal line, the more similar are the means and the shorter is the distance. Items in the top-right corner are mainly agreed on by both journalists and users, while items in the bottom-left corner are mainly not agreed on.

All in all, we find a high congruency between journalists and audience members regarding journalistic role conceptions at Süddeutsche Zeitung; only four of these show a difference of means larger than 0.5 (see Table 9.2). Both audience members and journalists agree on specific functions that news journalism by Süddeutsche Zeitung should fulfil. Accordingly, the tasks to explain and convey complex issues $(\Delta=0.17)$ as well as to criticize problems and grievances $(\Delta=-0.15)$ and report as objectively and precisely as possible $(\Delta=-0.20)$ have a high priority among both journalists and audience members (see also Fig. 9.1). This shows that both groups more or less agree on the traditional tasks of journalists as explainers of complex topics, as critics and as disseminators of objective information (see Hanitzsch 2011; Weischenberg et al. 2012). Moreover, there is also notable agreement on what is not seen as a journalistic task: audience members and journalists alike reject the idea that journalism should "provide the audience with the opportunity to maintain ties among themselves" (item 2).

This is not to say that journalists and users agree on everything and there are some notable differences in opinion: journalists agree more strongly than users that it is their task to concentrate on news and information that is interesting for the widest possible audience $(\Delta=0.65$; significant with $p<0.001$ ). Users, on the other hand, expect journalists to also act as watchdogs ("control politics, business and society") to a 
Table 9.2 Case study Süddentsche Zeitung: congruence of journalistic role conceptions among journalists and audience members

\begin{tabular}{|c|c|c|c|c|}
\hline $\begin{array}{l}\text { "What are your per- } \\
\text { sonal goals in your } \\
\text { profession?"/"Süddeutsche } \\
\text { Zeitung journalists should..." }\end{array}$ & $\begin{array}{l}\text { Journalists } \\
(n=128-136)\end{array}$ & Users $(n=476-510)$ & $\Delta$ & $t$ \\
\hline $\begin{array}{l}\text { 1. Encourage and moder- } \\
\text { ate discussion among the } \\
\text { audience }\end{array}$ & 2.77 & 2.81 & -0.03 & 0.30 \\
\hline $\begin{array}{l}\text { 2. Provide the audience with } \\
\text { the opportunity to main- } \\
\text { tain relationships among } \\
\text { themselves }\end{array}$ & 1.80 & 1.83 & -0.04 & 0.36 \\
\hline $\begin{array}{l}\text { 3. Build and maintain a rela- } \\
\text { tionship to the audience }\end{array}$ & 2.87 & 2.83 & 0.04 & 0.36 \\
\hline 4. Share positive ideals & 3.08 & 3.15 & -0.07 & 0.53 \\
\hline $\begin{array}{l}\text { 5. Inform the audience as } \\
\text { fast as possible }\end{array}$ & 3.98 & 4.06 & -0.08 & 0.82 \\
\hline $\begin{array}{l}\text { 6. Show new trends and } \\
\text { highlight new ideas }\end{array}$ & 3.90 & 3.78 & 0.13 & -1.27 \\
\hline $\begin{array}{l}\text { 7. Point out interesting top- } \\
\text { ics to the audience and show } \\
\text { them where to get further } \\
\text { information on them }\end{array}$ & 4.02 & 4.15 & -0.13 & 1.37 \\
\hline $\begin{array}{l}\text { 8. Criticize problems and } \\
\text { grievances* }\end{array}$ & 4.40 & 4.56 & -0.15 & 2.16 \\
\hline $\begin{array}{l}\text { 9. Give the audience the } \\
\text { opportunity to express } \\
\text { opinion on topics of public } \\
\text { interest }\end{array}$ & 2.82 & 3.00 & -0.17 & 1.53 \\
\hline $\begin{array}{l}\text { 10. Explain and convey } \\
\text { complex issues** }\end{array}$ & 4.78 & 4.61 & 0.17 & -3.17 \\
\hline $\begin{array}{l}\text { 11. Inform the audience as } \\
\text { objectively and precisely as } \\
\text { possible* }\end{array}$ & 4.33 & 4.53 & -0.20 & 2.43 \\
\hline $\begin{array}{l}\text { 12. Get into conversation } \\
\text { with the audience about cur- } \\
\text { rent events and topics* }\end{array}$ & 2.81 & 3.09 & -0.28 & 2.53 \\
\hline $\begin{array}{l}\text { 13. Present my/their own } \\
\text { opinion(s) to the audience/ } \\
\text { to the public*** }\end{array}$ & 3.19 & 3.55 & -0.36 & 3.34 \\
\hline $\begin{array}{l}\text { 14. Provide useful informa- } \\
\text { tion for the audience and act } \\
\text { as advisor/guidance*** }\end{array}$ & 3.02 & 2.56 & 0.46 & -4.02 \\
\hline
\end{tabular}


Table 9.2 (continued)

\begin{tabular}{|c|c|c|c|c|}
\hline $\begin{array}{l}\text { "What are your per- } \\
\text { sonal goals in your } \\
\text { profession?"/Sïddeutsche } \\
\text { Zeitung journalists should..." }\end{array}$ & $\begin{array}{l}\text { Journalists } \\
(n=128-136)\end{array}$ & Users $(n=476-510)$ & $\Delta$ & $t$ \\
\hline $\begin{array}{l}\text { 15. Provide people with } \\
\text { opportunity to publish their } \\
\text { own content }{ }^{* *}\end{array}$ & 1.79 & 2.29 & -0.50 & 5.01 \\
\hline $\begin{array}{l}\text { 16. Give the audience topics } \\
\text { to talk about }{ }^{* *}\end{array}$ & 3.98 & 3.47 & 0.52 & -4.91 \\
\hline $\begin{array}{l}\text { 17. Monitor politics, the } \\
\text { economy and society***}\end{array}$ & 2.90 & 3.49 & -0.58 & 4.19 \\
\hline $\begin{array}{l}\text { 18. Offer the audi- } \\
\text { ence entertainment and } \\
\text { relaxation } * * *\end{array}$ & 3.50 & 2.88 & 0.62 & -5.84 \\
\hline $\begin{array}{l}\text { 19. Concentrate on news } \\
\text { that is interesting to an audi- } \\
\text { ence as wide as possible }\end{array}$ & 3.35 & 2.70 & 0.65 & -5.99 \\
\hline
\end{tabular}

Items are sorted by size of difference in means $(\Delta)$. Scales were 5 -point Likert scale ranging from 1 ("strongly disagree") to 5 ("strongly agree"). Answers "Don't know./Can't say." were excluded for calculation of means. Tagged differences in means are statistically significant on levels: ${ }^{*} p<0.05$; ${ }^{* *} p<0.01 ;{ }^{* * *} p<0.001$

greater extent than journalists themselves feel professionally obliged to $(\Delta=-0.58, p<0.001)$.

Another dimension of our understanding of "inclusion distance" between journalists and their audiences is the congruence of the (assumed) importance of participatory features. Here we asked journalists what they consider important to their audiences and we also asked audiences members themselves. What is striking at first is that all differences in means are highly significant (see Table 9.3). Additionally, Fig. 9.3 indicates that in almost all cases journalists overestimate the importance the queried participation- and transparency-oriented features actually have for their audiences (=almost all items are situated right from the diagonal line) - or at least what they claim they have for them. 
Table 9.3 Case study Süddeutsche Zeitung: congruence of (assumed) importance of participatory features

\begin{tabular}{|c|c|c|c|c|}
\hline $\begin{array}{l}\text { "How important are the } \\
\text { following aspects to your audi- } \\
\text { ence/to you?" }\end{array}$ & $\begin{array}{l}\text { Journalists } \\
(n=119-129)\end{array}$ & Users $(n=480-515)$ & $\Delta$ & $t$ \\
\hline $\begin{array}{l}\text { 1. To be able to get further } \\
\text { information on editorial } \\
\text { routines and practices } * * *\end{array}$ & 2.95 & 2.51 & 0.44 & -4.22 \\
\hline $\begin{array}{l}\text { 2. To have editorial staff } \\
\text { introduced to them } / \mathrm{me}^{* * *}\end{array}$ & 3.26 & 2.78 & 0.48 & -4.55 \\
\hline $\begin{array}{l}\text { 3. To be able to quickly } \\
\text { forward and recommend } \\
\text { news items to friends and } \\
\text { family }{ }^{* *}\end{array}$ & 3.77 & 3.25 & 0.52 & -4.93 \\
\hline $\begin{array}{l}\text { 4. To have a platform for } \\
\text { discussing the practices and } \\
\text { quality of news reporting } * * *\end{array}$ & 3.57 & 3.03 & 0.54 & -4.93 \\
\hline $\begin{array}{l}\text { 5. To be able to provide own } \\
\text { material (pictures, videos, } \\
\text { interview questions) for } \\
\text { news reporting*** }\end{array}$ & 2.55 & 1.87 & 0.68 & -6.65 \\
\hline $\begin{array}{l}\text { 6. To be able to make sug- } \\
\text { gestions to the editorial staff } \\
\text { (e.g. on topics for reporting, } \\
\text { interview partners) }\end{array}$ & 3.29 & 2.56 & 0.73 & -7.38 \\
\hline $\begin{array}{l}\text { 7. To get additional infor- } \\
\text { mation on the sources the } \\
\text { reporting is based on*** }\end{array}$ & 3.15 & 3.89 & -0.75 & 7.06 \\
\hline $\begin{array}{l}\text { 8. To be able to see which } \\
\text { stories are viewed, shared } \\
\text { and commented on by many } \\
\text { other people }\end{array}$ & 3.24 & 2.46 & 0.78 & -7.51 \\
\hline $\begin{array}{l}\text { 9. To be able to interact } \\
\text { and/or make contact with } \\
\text { other readers/users and } \\
\text { exchange opinions } \\
* * *\end{array}$ & 3.01 & 1.93 & 1.08 & -10.23 \\
\hline $\begin{array}{l}\text { 10. To be able to rate and } \\
\text { comment on journalistic } \\
\text { content }{ }^{* * *}\end{array}$ & 3.95 & 2.81 & 1.13 & -11.49 \\
\hline $\begin{array}{l}\text { 11. To be able to make } \\
\text { contact and enter into a } \\
\text { dialogue with editorial staff } \\
\text { directly*** }\end{array}$ & 3.70 & 2.55 & 1.14 & -12.14 \\
\hline
\end{tabular}


Table 9.3 (continued)

\begin{tabular}{|c|c|c|c|c|}
\hline $\begin{array}{l}\text { "How important are the } \\
\text { following aspects to your audi- } \\
\text { ence/to you?" }\end{array}$ & $\begin{array}{l}\text { Journalists } \\
(n=119-129)\end{array}$ & Users $(n=480-515)$ & $\Delta$ & $t$ \\
\hline $\begin{array}{l}\text { 12. To have the editorial } \\
\text { staff be present and respon- } \\
\text { sive (on social media)***}\end{array}$ & 3.48 & 2.08 & 1.39 & -11.67 \\
\hline $\begin{array}{l}\text { 13. To be taken seriously by } \\
\text { journalists } * * *\end{array}$ & 4.63 & 3.24 & 1.40 & -16.03 \\
\hline $\begin{array}{l}\text { 14. To be able to publicly } \\
\text { show their/my attach- } \\
\text { ment to the Süddeutsche } \\
\text { Zeitung*** }\end{array}$ & 3.39 & 1.99 & 1.40 & -12.15 \\
\hline $\begin{array}{l}\text { 15. To be able to discuss } \\
\text { the topics of news reporting } \\
\text { with other readers/users } \\
* * *\end{array}$ & 3.83 & 2.34 & 1.48 & -15.92 \\
\hline
\end{tabular}

Items are sorted by size of difference in means $(\Delta)$. Scales were 5 -point Likert scale ranging from 1 ("very unimportant") to 5 ("very important"). Answers "Don't know./Can't say." were excluded for calculation of means. Tagged differences in means are statistically significant on levels: ${ }^{*} p<0.05$; ${ }^{* *} p<0.01 ;{ }^{* * *} p<0.001$

The only exception is item number 7 . For audience members, the most important thing is "to get additional information on the sources the reporting is based on", while, to some extent, journalists underestimate this desire for source transparency $(\Delta=-0.75, p<0.001)$. In contrast, they think that the most important thing for audiences is to be taken seriously - a desire that journalists overestimate as the user survey reveals $(\Delta=1.40, p<0.001)$. We also found a similar pattern in a case study on the German TV newscast "Tagesschau" (Heise et al. 2014). In sum, we only found four out of 15 items in this item battery that users rate important rather than unimportant $(=$ mean $>3.0)$ : the already mentioned item no. 7; 3 ("to be able to quickly forward and recommend news items to friends and family"); 13 ("to be taken seriously by journalists") and 4 ("to have a platform for discussing the practices and quality of news reporting").

The item with the most significant difference of means is the possibility of discussing the topics of news reporting with other users $(\Delta=1.48)$. While journalists expect this aspect to be more important for audience members, users care less about it and deem it rather unimportant. 


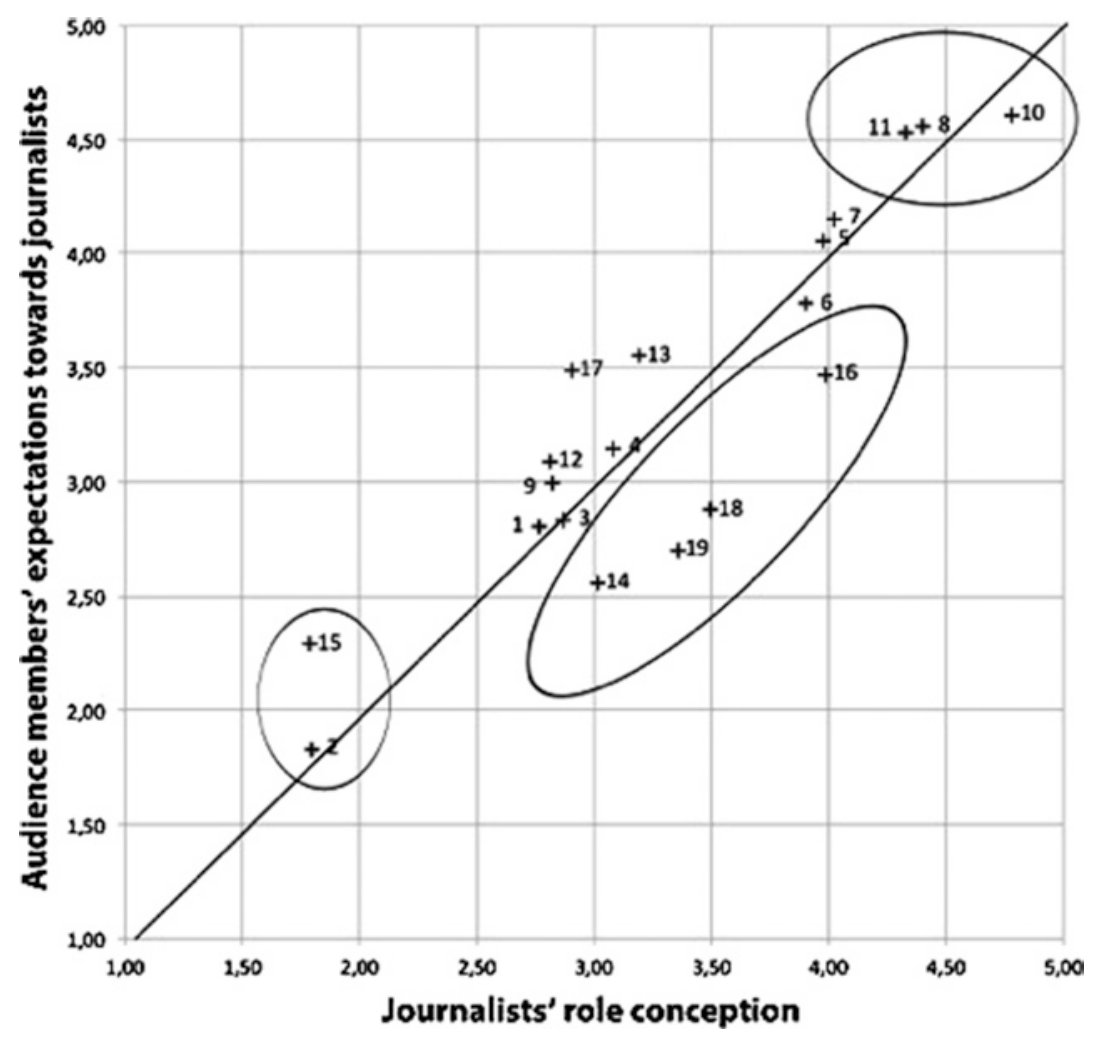

Fig. 9.2 Case study Süddeutsche Zeitung: journalistic role conception among journalists and audience members (numbers refer to items in Table 9.2)

In sum, both findings leave a mixed impression. The inclusion distance, in other words the difference between inclusion expectations as far as journalists and audiences are concerned, is rather low with respect to journalistic role conceptions. Journalists at the Süddeutsche Zeitung tend to wholeheartedly lend their support to role perceptions that are related to the concept of objective reporting (e.g. "inform the audience as objectively and precisely as possible") and partly to advocacy journalism ("criticize problems and grievances") (Weischenberg et al. 2012: 213) and this, in the view of their audience, is exactly what they should be doing. The comparison of the (assumed) importance of particular aspects of audience participation, however, shows a rather obvious inclusion 
distance. With respect to almost all aspects, journalists assume a greater interest in participation- and transparency-oriented practices than users specify for themselves. The only exception here is an aspect that relates source to transparency: audience members have significantly higher expectations of acquiring additional information and references to the sources of a news story than journalists anticipate.

\subsection{Conclusions}

We have discussed here empirical evidence of a transformation that is taking place in the journalism-audience relationship through the examples of three different studies that focused, first, on the anticipated expectations of journalists in newspaper newsrooms concerning their audience and, second, on the comparison of expectations of journalists in a newsroom with those of their audience. The survey results indicate that the transformation of the journalism-audience relationship is a complex, non-linear and quite ambivalent process that is moulded by a plethora of factors that have primarily social determinants. They are deeply rooted and interrelated with what journalists want to achieve professionally and what they should according to audiences. With the help of the communicative figurations approach, we can describe the implications of these interdependencies as follows:

1. The constellation of actors in an increasingly fragmented and diverse public sphere contribute to journalists' construction of their image of and their relationship to audiences, including, among others, audience members themselves who contact journalists, write online comments, collaborate in investigating issues and so on, as well as social media editors and other colleagues who provide information about the audience. Analyses of the surveys showed that journalists assess the feedback they receive by members of the audience as valuable and guiding. However, this has rather limited implications for the willingness of journalists to allow users to participate in their editorial work beyond appreciating their feedback. Nevertheless, journalists learn a lot about their fragmented audience that has already developed into multiple audiences against the background of the proliferation of channels and platforms in the digital media environment where journalism is distributed, consumed, shared and discussed. Newsrooms no longer serve a 


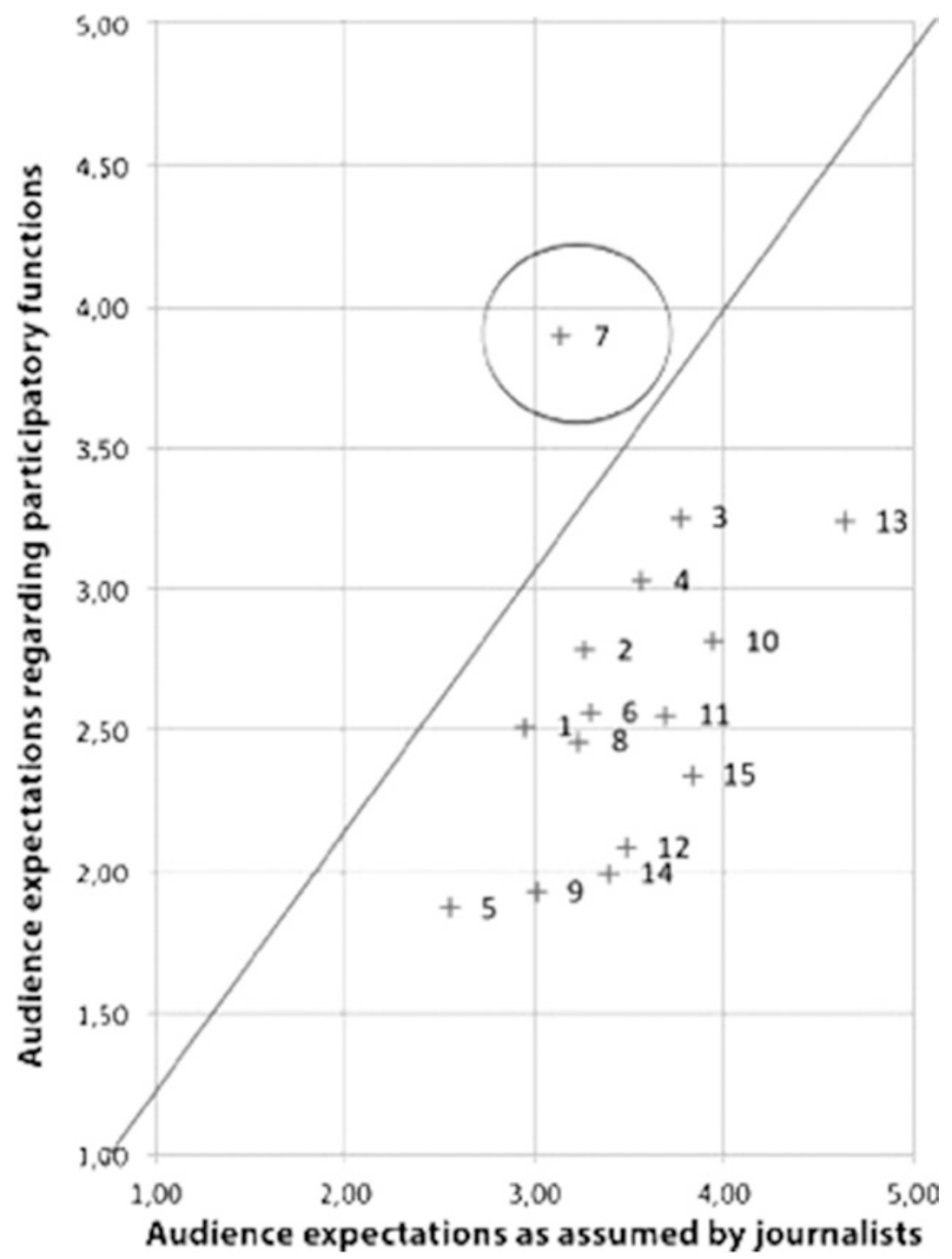

Fig. 9.3 Case study Sïddeutsche Zeitung: congruence of (assumed) importance of participatory features (numbers refer to items in Table 9.3) 
coherent audience, but have to approach their (different) target groups at various levels through different routes in order to reach them, catch their attention and increase audience loyalty and retention. Therefore, as the survey results underline, journalism has already become more dialogue oriented and more open towards the (online) social interaction of its audiences.

2. Newsrooms have eagerly adapted to new communicative practices, that is, modes of communication, to reach their audiences on diverse media channels and platforms (the respective media ensemble). This is mainly the product of a learning process that has been stimulated by changing habits of media use: as social media have become more relevant in both private and public communications, so has the information seeking and entertainment needs among all age groups - especially for adolescents and young adults - journalists try to adapt to and explore new ways of distributing their content and engaging (with) their audiences on social media platforms. Social networks - along with their versatile communication, information and entertainment tools - have entered the newsroom and are used by journalists in various ways in their editorial work. Even more importantly, newsrooms are beginning to systematically develop their own journalistic distribution and audience engagement strategies for communicative forms that are popular among audiences, such as interpersonal direct messaging and chatting (text/video).

3. Consequentially, journalism undergoes a profound transformation with respect to the dominant frames of relevance that guide these practices, including the (shared) understandings of (1) the journalist's role in his/her organizational environment(s), (2) the position of the respective organization(s) in the wider journalistic field and (3) the function of journalism for society as a whole. As the survey results indicate, newsrooms become an increasingly contested field of interrelated individual and organizational levels of journalistic role conceptions that are, on the one hand, oriented towards 'information supply and demand' (with a hesitation to let the reader participate in editorial work), or on the other, towards 'dialogue and participation' (with a stronger emphasis on the moderating role and a more conversational mediation of information). At a glance, journalism experiences a vast expansion of professional self-perceptions and role expectations among audiences 
oriented towards dialogue and participation. However, these new roles do not displace traditional expectations towards journalism, but instead contribute to a differentiation of expectations towards journalists even though the majority of the audience might not be overly interested in participating editorially.

Considering these profound aspects of the transformation of the journalism-audience relationship as demonstrated by the results of the three separate surveys, our three hypotheses turned out to be fairly accurate.

Our first hypothesis assumed that the communicative orientation between journalism and its audiences would be characterized by a combination of a rather monological approach and an increasingly dialogic relation to audiences. The empirical data not only demonstrate this blending of communicative orientations to be accurate, but also highlight that there are different sets of priorities regarding the insistence of promoting social media-oriented strategies in newsroom work that depend on the perceived needs and demands of different target groups.

The second hypothesis was concerned with shifts and diversifications in perceptions within the newsroom that might lead to a dynamization of the communicative journalism-audience relationship. By analyzing the survey data, we found that there is indeed an emergence of new roles in newsrooms that is being accepted by journalists as a reaction to the shifting media environment characterized by popular social media that require additional editorial tasks to be able to reach and inform audiences properly. However, the empirical data also show that this one-sided dynamization of self-perceptions is not (yet) reflected by a more reflexive understanding between journalists and audiences - especially when it comes to audience participation: journalists and audiences do not necessarily know what the other wants, what they deem important and what they expect from each other. Rather, journalists seem to pursue a fairly one-sided approach of adding more dynamism to their relationship with their audiences and trying to meet their assumed expectations. This suggests that the journalism-audience relationship is not (yet) characterized by a communicative exchange that leads to a deeper understanding of each other's needs and demands.

Our third hypothesis focused on the asymmetry between journalism and audiences in terms of supply and demand which could be complemented by a more dialogue and participation-oriented framing and reciprocity. The analyzed data show that journalists are not completely ready 
to share the details of their editorial work. Most journalists see the necessity of explaining the background and context of their reporting with their audiences to a certain degree, but not to engage readers in sovereign newsroom activities such as taking part in editorial conferences, discussing and selecting issues to report on or in fact checking articles. This shows that there is still a considerable communicative distance between newsrooms and audiences with respect to tasks that are deemed exceptionally relevant to the professional self-understanding of journalists in their traditional privileged role as (mass media) gatekeepers and agenda setters.

Overall, we can conclude that journalism is going through a transition phase that challenges the established roles, tasks and even functions traditionally ascribed to journalists and to journalism as a social system or field. In this chapter, we have discussed empirical evidence indicating that as journalists grow accustomed to and more intensely consider new dialogic tasks as important in prospective newsroom work and the more that they integrate social media communication in their editorial work, the more likely it is that legacy news media change profoundly in their communicative orientation and refresh their journalism-audience relationship in light of new media use.

\section{Notes}

1. See, as an example, a study on the British Guardian's comment section published under the title: "The dark side of Guardian comments". Here, the gender of authors and the topical area of an article were found to be predictors of attraction to hateful comments. https://www.theguardian. com/technology/2016/apr/12/the-dark-side-of-guardian-comments. Accessed: 30 Mar 2017.

2. For examples see the list on news organizations that shot down onsite comments collected by the "Coral Project": https://community.coralproject.net/t/shutting-down-onsite-comments-a-comprehensive-list-of-allnews-organisations $/ 347$.

3. The study "Die Zeitungsmacher" ['The Newspaper Makers'] was conducted in 2012 among newsrooms with complete editorial team ("publizistische Einheiten") of all German daily newspapers (130). The sample has been generated randomly by a multistage selection process with different size classes on newsroom level (one, two or three journalists each). The response was 56.2 per cent with a total of 127 journalists in the sample. Study was funded by the Foundation Press House NRZ, the OttoBrenner-Foundation and the FAZIT Foundation. 
4. The study on millennial news media was conducted in 2016 (Kramp 2017; Kramp/Weichert 2017; Weichert/Kramp 2017a; 2017b). The empirical multi-method design included expert interviews with editors-in-chief of millennial news media in Germany, focus groups with participants of four different birth cohorts (1981-1985, 1986-1991, 1992-1996, 19972000) and in-depth interviews with participants of the focus groups, combined with network maps and media diaries. The study was commission by the Federation of German Newspaper Publishers (BDZV). For this chapter, we analyzed the interviews with the following editors-in-chief (in the order of interview date): Sebastian Horn (Ze.tt), Juliane Leopold (Buzzfeed Germany), Christian Helten (jetzt), Christian Grospitz (BUNTEnow), Hans-Jürgen Jakobs (orange by Handelsblatt), Manfred Hart (BYou), Sebastian Matthes (HuffingtonPostGermany), Tom Littlewood (Vice Germany), Volker Pfau (Headline24) and Nora Beckerhaus (Refinery29).

5. This kind of systematic inclusion of the audience in editorial research is being tested by the foundation-funded newsroom Correct! $\mathrm{v}$ on its online platform crowdnewsroom.org. An exemplary research collaboration between the journalists in the newsroom and members of the audience has led to the publication of an investigative dossier on the situation of German saving banks ("Sparkassen").

6. The project was based on theoretical assumptions and analytical heuristics derived from sociological inclusion theory (Loosen and Schmidt 2012). In a nutshell, audience inclusion into journalism is realized through both inclusion practices (e.g. certain patterns of media use) and inclusion expectations (e.g. assumptions about the professional role of journalists), which can be assessed for either journalists or audience members. The central methodological innovation of the project was to systematically relate and connect methods focusing on either side in order to address the relationship between them.

7. Items were partly drawn from established scales, partly created by the research team. A documentation of the survey instruments can be found in our project blog at http://jpub20.hans-bredow-institut.de/?p=768.

\section{REFERENCES}

Albert, Mathias, Klaus Hurrelmann, Gudrun Quenzel, and TNS Infratest Social Research. 2015. Jugend 2015. 17. Shell Jugendstudie [Youth 2015. 17th Shell youth study]. Frankfurt am Main: Fischer TB.

American Press Institute, Associated Press, and NORC Center for Public Affairs Research. 2015. How millennials get news: Inside the habits of America's first digital generation. Media insight project, March 2015. http://www. 
mediainsight.org/PDFs/Millennials/Millennials\%20Report\%20FINAL.pdf. Accessed 30 Mar 2017.

Bakker, Piet. 2014. Mr. Gates returns: Curation, community management and other new roles for journalists. Journalism Studies 15 (5): 596-606.

Bergström, Annika, and Ingela Wadbring. 2015. Beneficial yet crappy: Journalists and audiences on obstacles and opportunities in reader comments. European Journal of Communication 30 (2): 137-151.

Birkner, Thomas. 2012. Das Selbstgespräch der Zeit. Die Geschichte des Journalismus in Deutschland 1605-1914 [The self-talk of time. The history of journalism in Germany 1605-1914]. Köln: von Halem.

Bruns, Axel. 2005. Gatewatching. Collaborative online news production. New York: Peter Lang.

Carvajal, Miguel, José A. García-Avilés, and José L. González. 2012. Crowdfunding and non-profit media. The emergence of new models for public interest journalism. Journalism Practice 6 (5-6): 638-647.

Cassidy, William P. 2005. Variations on a theme: The professional role conceptions of print and online newspaper journalists. Journalism \& Mass Communication Quarterly 82 (2): 264-280.

Collins, Luke, and Brigitte Nerlich. 2015. Examining user comments for deliberative democracy: A corpus-driven analysis of the climate change debate online. Environmental Communication 9 (2): 189-207.

Deloitte. 2016. The 2016 Deloitte Millennial Survey. https://www2.deloitte. $\mathrm{com} /$ content/dam/Deloitte/global/Documents/About-Deloitte/gx-millenial-survey-2016-exec-summary.pdf. Accessed 30 Mar 2017.

Deuze, Mark, Axel Bruns, and Christoph Neuberger. 2007. Preparing for an age of participatory news. Journalism Practice l (3): 322-338.

Duggan, Maeve. 2015a. Mobile messaging and social media 2015. Pew Research Center, 19.08.2015. http://www.pewinternet.org/2015/08/19/mobilemessaging-and-social-media-2015/. Accessed: 30 Mar 2017.

Duggan, Maeve. 2015b. The demographics of social media users. Pew Research Center. 19.08.2015. http://www.pewinternet.org/2015/08/19/the-demographics-of-social-media-users/. Accessed: 30 Mar 2017.

Esser, Frank, and Michael Brüggemann. 2010. The changing business of journalism and its implications for democracy: The case of Germany. In The changing business of journalism and its impact on democracy, ed. David A.L. Levy and Rasmus K. Nielsen, 39-54. Oxford: Reuters Institute for the Study of Journalism.

Hanitzsch, Thomas. 2011. Populist disseminators, detached watchdogs, critical change agents and opportunist facilitators: Professional milieus, the journalistic field and autonomy in 18 countries. International Communication Gazette 73 (6): 477-494. 
Hasebrink, Uwe. 2008. Das multiple Publikum. Paradoxien im Verhältnis von Journalismus und Mediennutzung. In Paradoxien des Journalismus. TheorieEmpirie - Praxis, ed. Bernhard Pörksen, Wiebke Loosen, and Armin Scholl, 513-530. Wiesbaden: VS.

Hasebrink, Uwe, and Andreas Hepp. 2016. How to research cross-media practices? Investigating media repertoires and media ensembles. Communicative Figurations Working Paper Series 15. http://www.kommunikative-figurationen.de/fileadmin/redak_kofi/Arbeitspapiere/CoFi_EWP_No-15_ Hasebrink_Hepp.pdf. Accessed 30 Mar 2017.

Heinrich, Ansgar. 2011. Network journalism. Journalistic practice in interactive spheres. New York, Oxford: Routledge.

Heise, Nele, Wiebke Loosen, Julius Reimer, and Jan-Hinrik Schmidt. 2014. Including the audience. Comparing attitudes and expectations of journalists and users towards participation in German TV news journalism. Journalism Studies 15 (4): 411-430.

Hepp, Andreas, and Uwe Hasebrink. 2014. Human interaction and communicative figurations: The transformation of mediatized cultures and societies. In Mediatization of communication, ed. Knut Lundby, 249-272. Berlin, New York: de Gruyter.

Hermida, Alfred. 2014. Open journalism: Dynamics of change and continuity in news work in the 21st century. Doctoral thesis. City University London.

Klinenberg, Eric. 2005. Convergence: News production in a digital age. Convergence 597 (1): 48-64.

Kramp, Leif. 2015. The rumbling years. The communicative figurations approach as a heuristic concept to study - and shape - the transformation of journalism. In Journalism, representation and the public sphere, ed. Leif Kramp, Nico Carpentier, Andreas Hepp, Ilija Tomanić Trivundža, Hannu Nieminen, Risto Kunelius, Tobias Olsson, Ebba Sundin, and Richard Kilborn, 23-55. Bremen: edition lumière.

Kramp, Leif. 2016. Conceptualizing metropolitan journalism: New approaches, new communicative practices, new perspectives? Communicative Figurations Working Paper Series 10. March 2016. http://www.kommunikative-figurationen.de/fileadmin/redak_kofi/Arbeitspapiere/CoFi_EWP_No-10_Kramp. pdf. Accessed 30 Mar 2017.

Kramp, Leif, and Stephan Weichert. 2015. From crisis to departure? Newsroom culture under the impact of digital structural change in Germany. Paper presented at the 2015 Negotiating Culture Conference: News Production Culture, Reuters Institute for the Study of Journalism at the University of Oxford. 30.10.2015. Oxford.

Kramp, Leif, and Stephan Weichert. 2016. Understanding the millennial way: Implications of young users' volatile media practices for journalism practice. Paper presented at the 2016 European Communication Research and Education Association's Biannual Conference, 11.11.2016, Prague, CZ. 
Kramp, Leif. 2017. "We need to keep moving": Strategies of news media to attract young audiences in Germany. In Present scenarios of media production and engagement, ed. Simone Tosoni, Nico Carpentier, Maria Francesca Murru, Richard Kilborn, Leif Kramp, Risto Kunelius, Tobias Olsson, Pille Pruulmann-Vengerfeldt, 107-122. Bremen: edition lumière.

Kramp, Leif, and Stephan Weichert. 2017. Der Millennial Code. Junge Mediennutzer verstehen - und bandeln [The millennial code. Understanding young media users - and act]. Leipzig: Vistas.

Lewis, Seth C. 2012. The tension between professional control and open participation. Journalism and its boundaries. Information, Communication \& Society 15 (6): 836-866.

Loosen, Wiebke 2016. Publikumsbeteiligung im Journalismus [Audience participation in journalism]. In Journalismusforschung. Stand und Perspektiven [Journalism research], ed. Klaus Meier and Christoph Neuberger, 287-316. Baden-Baden: Nomos.

Loosen, Wiebke. 2015. The notion of the 'blurring boundaries': Journalism as a (de-)differentiated phenomenon. Digital Journalism 3 (1): 68-84.

Loosen, Wiebke, and Jan-Hinrik Schmidt. 2012. (Re-)discovering the audience. The relationship between journalism and audience in networked digital media. Information, Communication \& Society 15 (6): 867-887.

Loosen, Wiebke, and Jan-Hinrik Schmidt. 2016a. Multi-method approaches. In The Sage handbook of digital journalism, ed. Tamara Witschge, Chris W. Anderson, David Domingo, and Alfred Hermida, 562-575. London et al.: Sage.

Loosen, Wiebke, and Jan-Hinrik Schmidt. 2016b, forthcoming. Between proximity and distance: Including the audience in journalism (research). In The Routledge companion to digital journalism studies, ed. Bob Franklin and Scott Eldridge II. New York, London: Routledge.

Meijer, Irene Costera, and Tim Groot Kormelink. 2015. Checking, sharing, clicking and linking. Changing patterns of news use between 2004 and 2014. Digital Journalism 3 (5): 664-679.

Meijer, Irene Costera. 2016. Practicing audience-centred journalism research. In The SAGE Handbook of Digital Journalism, eds Tamara Witschge, C.W. Anderson, David Domingo, and Alfred Hermida, 546-561. London: SAGE Publications.

Mellado, Claudia. 2011. Modeling individual and organizational effects on Chilean journalism: A multilevel analysis of professional role conceptions. Comunicación y Sociedad 24 (2): 269-304.

Mellado, Claudia, and Arjen van Dalen. 2013. Between rhetoric and practice: Explaining the gap between role conception and performance in journalism. Journalism Studies 15 (6): 859-878.

Mellado, Claudia, Lea Hellmueller, and Wolfgang Donsbach. 2017. Journalistic role performance. Concepts, contexts, and methods. New York, Oxon: Routledge. 
Mitchelstein, Eugenia, and Pablo J. Boczkowski. 2009. Between tradition and change. A review of recent research on online news production. Journalism 10 (5): 562-586.

Neuberger, Christoph, Susanne Langenohl, and Christian Nuernbergk. 2014. Social Media und Journalismus [Social media and journalism]. Düsseldorf: LfM.

Newman, Nic, Richard Fletcher, David A. L. Levy, and Rasmus K. Nielsen. 2016. Reuters institute digital news report 2016. Oxford: Reuters Institute for the Study of Journalism. http://reutersinstitute.politics.ox.ac.uk/sites/ default/files/Digital-News-Report-2016.pdf. Accessed 30 Mar 2017.

Paulussen, Steve. 2012. Technology and the transformation of news work: Are labor conditions in (online) journalism changing? In The handbook of global online journalism, ed. Eugenia Siapera, and Andreas Veglis, 192-208. Malden, MA: Wiley.

Phillips, Angela. 2015. Journalism in context. Practice and theory for the digital age. Abingdon, New York: Routledge.

Poindexter, Paula M. 2012. Millennials, news, and social media. Is news engagement a thing of the past? New York: Peter Lang.

Reader, Bill. 2015. Audience feedback in the media. London, New York: Routledge.

Robinson, Sue. 2010. Traditionalists vs. convergers. Textual privilege, boundary work, and the journalist-audience relationship in the commenting policies of online news sites. Convergence: The International Journal of Research into New Media Technologies 16 (1): 125-143.

Schmidt, Jan-Hinrik, and Wiebke Loosen. 2015. Both sides of the story. Assessing audience participation in journalism through the concept of inclusion distance. Digital Journalism 3 (2): 259-278.

Schoenbach, Klaus, Edmund Lauf, Dieter Stürzebecher, and Silvia Knobloch. 1999. Evaluating 350 newspapers - Factors contributing to their success: A summary of a large-scale empirical study. Document Design l (2): 75-84.

Singer, Jane B., Alfred Hermida, David Domingo, Ari Heinonen, Steve Paulussen, Thorsten Quandt, Zvi Reich, and Marina Vujnovic. 2011. Participatory journalism. Guarding open gates at online newspapers. Chichester: Wiley.

van Dalen, Arjen, Claes H. de Vreese, and Erik Albæk. 2012. Different roles, different content? A four-country comparison of the role conceptions and reporting style of political journalists. Journalism 13 (7): 903-922.

Venkatesch, Alladi, and Debora Dunkle. 2013. Digitizing physical objects in the home. In The Routledge companion to digital consumption, ed. Russell W. Belk, and Rosa Llamas, 14-27. Oxon, New York: Routledge.

Weaver, David H., and G. Cleveland Wilhoit. 1986. The American journalist: A portrait of U.S. news people and their work. Bloomington: Indiana University Press. 
Weichert, Stephan, Leif Kramp, and Martin Welker. 2015. Die Zeitungsmacher. Aufbruch in die digitale Moderne [The newspaper makers]. Wiesbaden: Springer VS.

Weichert, Stephan, and Leif Kramp. 2017a. Millennials. Mediennutzungsverhalten und Optionen für Zeitungsverlage [Millennials. Media use behaviour and options for newspaper publishers]. Berlin: BDZV.

Weichert, Stephan, and Leif Kramp. 2017b. Trendreport 2020. Medien für Millennials [Trend report 2020. Media for millennials]. Berlin: BDZV.

Weischenberg, Siegfried, Maja Malik, and Armin Scholl. 2012. Journalism in Germany in the 21 st century. In The global journalist in the 21st century, ed. David H. Weaver, and Lars Willnat, 205-219. Mahwah: L. Erlbaum Associates.

Open Access This chapter is licensed under the terms of the Creative Commons Attribution 4.0 International License (http://creativecommons.org/licenses/ by $/ 4.0 /$ ), which permits use, sharing, adaptation, distribution and reproduction in any medium or format, as long as you give appropriate credit to the original author(s) and the source, provide a link to the Creative Commons license and indicate if changes were made.

The images or other third party material in this chapter are included in the chapter's Creative Commons license, unless indicated otherwise in a credit line to the material. If material is not included in the chapter's Creative Commons license and your intended use is not permitted by statutory regulation or exceeds the permitted use, you will need to obtain permission directly from the copyright holder.

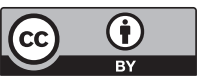

